\title{
Diabetes in der Familie macht Sport mühsamer
}

\author{
Diabetiker tun sich schwerer mit körperlicher Aktivität als Gesunde. Dem könnte eine genetische Prä- \\ disposition zugrunde liegen, die auch schon im vordiabetischen Stadium zu Beeinträchtigungen führt.
}

_ Forscher aus Malmö untersuchten 35 nicht-diabetische Männer, von denen 16 eine positive Familienanamnese für Diabetes hatten. Die Teilnehmer waren sich hinsichtlich Alter, maximaler Sauerstoffaufnahme $\left(\mathrm{VO}_{2} \max \right)$ und BodyMass-Index ähnlich. Alle durchliefen eine Intervention zur Steigerung körperlicher Aktivität über sieben Monate, im Schnitt 39 Einheiten. Vor- und nachher wurden sie körperlich untersucht. Sie machten einen oralen Glukosetoleranztest und ließen sich für Expressionsanalysen Muskelbiopsien entnehmen.

Beim Vergleich der Fitness stellte sich heraus, dass mithilfe der Intervention das $\mathrm{VO}_{2}$ max im Schnitt um 14\% zu- und das Körpergewicht um 1,2 kg abgenommen hatten. Die Teilnehmer mit positiver Familienanamnese verbrauchten beim Training allerdings $61 \% \mathrm{mehr}$ Energie. Interessanterweise hatte dieser gesteigerte Verbrauch keinen stärkeren Effekt auf die anthropometrischen und metabolischen Parameter.

In der Gruppe ohne positive Familienanamnese zeigten bestimmte Gene eine stärkere Expression, die in Stoffwechselprozesse, oxidative Phosphorylierung und Zellatmungsprozesse involviert sind.

- Ekman C, Elgzyri T, Ström Ket al. Less pronounced response to exercise in healthy relatives to type 2 diabetics compared to controls. J Appl Physiol (1985). 2015;119:953-60

\section{KOMMENTAR}

Die viel stärker exprimierten "diabetespräventiven"Gene der Probanden ohne Familienanamnese sind ein klarer Hinweis auf ein reduziertes Diabetesrisiko, während eine Familienanamnese bei (noch) Gesunden physiologische Stoffwechselprozesse negativ zu beeinflussen scheint. Betroffene Personen sollten also Sport treiben oder auch intensiv die Alltagsaktivität steigern, um den genetischen Nachteil zu kompensieren.

Trotz einer positiven Familienanamnese ist der Diabetes keine Unausweichlichkeit. Die Quintessenz ist, dass Maßnahmen zur Diabetesprävention bei diesen Menschen besonders hohe Priorität haben sollte.

Prof. Dr. med. P. Schwarz

\section{Der Denker kackt besser}

Die Ursachen der chronischen Obstipation sind vielfältig, doch weist ein Teil der Patienten anorektale Entleerungsstörungen mit dem Gefühl der inkompletten Entleerung oder Blockade auf. Eine Studie aus Japan zeigt eine einfache, potenziell hilfreiche Maßnahme auf. 22 Patienten ohne Rektozele oder andere anatomische Auffälligkeiten wurden zweimal einer CTDefäkografie unterzogen - einmal in der normalen Sitzposition (Abb. A), einmal in der Position des berühmten "Denkers" von Auguste Rodin (Abb. $B, C)$. Dabei wurden jeweils der anorektale Winkel, der Abstand zwischen perinealer Ebene und Anus und die Länge des M. puborectalis vermessen. In der normalen Position wurde bei allen Patienten eine anorektale Entleerungsstörung diagnostiziert. In der Denkerposition nahmen alle drei Messparameter signifikant zu, und 15 Patienten konnten die kontrastmittelhaltige Paste vollständig ausscheiden. Bei 14 der Patienten kam es auch subjektiv zu einer Normalisierung der dyssynergen Entleerungsstörung und zu einem befriedigenden Entleerungsgefühl.

Jenseits aller messtechnischen Änderungen kommt es bei diesem Thema vor allem auf das subjektive Empfinden der Patienten an. Die Denker-Position bietet hier offensichtlich entscheidende Vorteile. Nebenwirkungen und Kosten sind nicht zu erwarten, sodass alle Patienten mit anorektaler Entleerungsstörung auf diese Möglichkeit hingewiesen und ständig daran erinnert werden sollten. Vielleicht hilft ja eine kleine Replik der Bronzeplastik von Rodin auf der Toilette.

Prof. Dr. med. H. S. FüeßI

- Takano S, Sands DR. Influence of body posture on defecation: a prospective study of "The Thinker" position. Tech Coloproctol. 2016;20:117-21
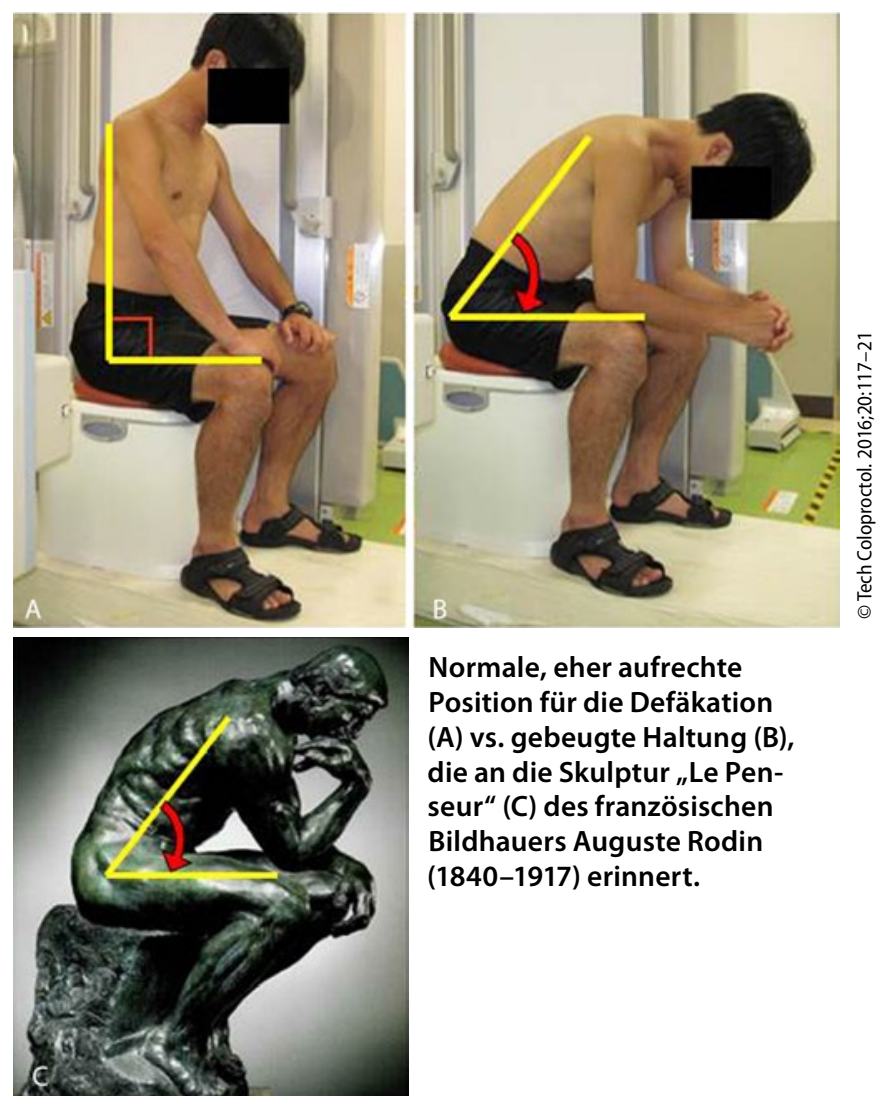

Normale, eher aufrechte Position für die Defäkation (A) vs. gebeugte Haltung (B), die an die Skulptur "Le Penseur" (C) des französischen Bildhauers Auguste Rodin (1840-1917) erinnert. 